\title{
LA UTOPÍA REFORMADORA DE LA SEGUNDA REPÚBLICA: LA LABOR DE MARCELINO PASCUA AL FRENTE DE LA DIRECCIÓN GENERAL DE SANIDAD, 1931-1933
}

\author{
Josep Bernabeu Mestre \\ Departament de Salut Pública [Història de la Ciència]. Universitat d'Alacant.
}

\section{INTRODUCCIÓN}

En noviembre de 1932 la Revista de Sanidad e Higiene Pública (1932, 7/11, 1148-1149) abría su sección de Noticias con una gacetilla en la que se informaba del homenaje que se había ofrecido al Director general de Sanidad, Marcelino Pascua Martínez (1897-1977). La comida homenaje había tenido lugar en el Hotel Ritz de Madrid, y a la misma habían asistido más de quinientos comensales. Entre los asistentes se encontraban los ministros Fernando de los Ríos e Indalecio Prieto.

La Comisión organizadora del homenaje, formada entre otros por Blas Cabrera, José Ortega y Gasset, Sebastián Recasens, decano de la Facultad de Medicina de Madrid, Gregorio Marañón, Verdes Montenegro, Gustavo Pittaluga y Julio Bejarano, destacaba en una nota de prensa la labor de reconstrucción de la Sanidad pública que había emprendido Marcelino Pascua desde el momento en que se hizo cargo, en abril de 1931, de la Dirección general de Sanidad. Llamaban la atención sobre la moderna orientación científica y la clara visión que tenía del problema sanitario español, así como sus dotes de organizador e intensa preparación científica. Con la llegada de Pascua a la Dirección gene-

Correspondencia:

Departament de Salut Publica

Universidad de Alicante

Apartado de Correos 99

03080 Alicante ral, afirmaban los organizadores del acto, la Sanidad nacional había iniciado una nueva etapa. La nota informativa finalizaba con estas palabras: Nada más justo que ofrecerle en una comida el cordial testimonio, la admiración y el agradecimiento de todos los que nos interesamos sinceramente -técnicos y profanos- por el progreso de la Sanidad pública en España.

El homenaje coincidía con uno de los momentos de mayor crispación política del primer bienio republicano, y más concretamente con el enfrentamiento que mantenían los socialistas (en el gobierno republicano-socialista de Azaña) y los republicanos radicales de Lerroux (en la oposición) (Ruiz Manjón, 1976: 316-321). Hay que destacar, además, la ausencia en el acto de homenaje del ministro de la Gobernación, dependencia de la que dependía la Dirección general de Sanidad. La cartera de Gobernación era ocupada por Santiago Casares Quiroga, de la Federación Republicana Gallega, quien había substituido a Miguel Maura en la crisis ministerial de octubre de 1931 (Ruiz Manjón, 1976: 246-248).

La crispación política que dominaba la escena política nacional, agudizaba el acoso a que estaba siendo sometido Marcelino Pascua por parte de la Asociación de Sanitarios Titulares. No hay que olvidar el papel destacado y la influencia del colectivo de médicos titulares en las filas del Partido Republicano Radical. Los radicales llegaron a contar con un grupo técnico de «clases sanitarias» que 
dependía de la Secretaría del Partido (Ruiz Manjón, 1976: 644-645) ${ }^{1}$.

En cierto modo, la comida homenaje a la que hemos hecho referencia además de testimoniar el reconocimiento a la labor de Pascua como responsable de la Sanidad Nacional, tenía un claro transfondo político y no era ajena al enfrentamiento y a la polémica que se había generado entre Pascua y el colectivo de médicos titulares que reivindicaba su pase a funcionarios del Estado. Las palabras pronunciadas por Gregorio Marañon en dicha comida no dejan lugar a dudas (Homenaje al doctor Pascua, 1932):

El doctor Pascua ha sido muy combatido. No creo impertinencia el recordarlo. Para crear las bases de un nuevo estado de cosas hay que herir o molestar a muchos: a todos los que representan en la organización social la herrumbre de las máquinas gastadas. Es dificil, acaso heroico, asumir este papel. Y más cuando se pertenece a la misma clase profesional de los perjudicados $[\ldots]$ ¿Adelante,

(1) La publicación Vida Médica (1933; XII (383): 5) al recoger la noticia del cese de Marcelino Pascua, afirmaba que se había producido como consecuencia de la ley de incompatibilidades y del acuerdo adoptado por la comisión ejecutiva del partido socialista, para añadir a continuación: suponemos el efecto que la lectura de esta noticia habrá de causar en el ánimo de los médicos titulares, tan esperanzados un día por las promesas del doctor Pascua como desilusionados hoy ante la realidad del Reglamento, la última desdichada obra del hombre que no supo corresponder al crédito de confianza que durante muchos meses le hubieron de conceder sus compañeros [... la Asociación de Titulares se puede afirmar que ha muerto a manos del doctor Pascua, al menos con su carácter de oficial, ya que al ser privada del Escalafón Isicl y de la expedición de documentos para la ficha de méritos se le han regado sus fuentes de ingresos más saneadas y seguras.

Sobre el modelo sanitario que se defendía desde las filas del Partido Republicano Radical, pueden consultarse diversos trabajos publicados en la revista Vida Médica: El Partido Radical, la sanidad y los técnicos (Muñoz Antuñano, 1932), El ministerio de Sanidad (1933) y La Sanidad pública (Estadella Arnó, 1933). Además, la relación entre los republicanos radicales y algunos medios de la prensa profesional resultaba más que evidente (Domínguez, 1932). En otoño de 1933, con motivo de la convocatoria de elecciones generales, la revista Vida Médica, bajo el título de Política sanitaria (1933: 3), afirmaba, refiriéndose al Partido Republicano Radical: El ideal sería que en las elecciones pudieran actuar verdaderos candidatos sanitarios; sin ninguna otra significación politica; ya que eso no puede ser, cuidemos de otorgar nuestra confianza y nuestros votos a los candidatos políticos que se comprometan, por sí o por sas partidos, a la defensa de la ransa sanitaria. pues, doctor Pascua? No hemos venido aquí a honrar un labor terminada. Lo que ahora se empieza tardará decenios en alcanzar su fin, y ésta es otra de las glorias de nuestro tiempo [...] Y hemos venido aquí para decírselo a él y por decirselo al Gobierno que le sostiene $y$ empuja. Y eso es todo

Los hechos que acabamos de resumir nos sitúan, como ya hemos indicado, en uno de los momentos políticos más delicados del llamando bienio transformador. Alcalá Zamora no supo comprender que la alianza republicanasocialista o terminaba su obra consolidando la República recién nacida o el régimen entraba en la vía del fracaso (Tamames, 1988: 20-24). Don Niceto pensó que tal vez un giro al centro permitiría esa consolidación en condiciones más idóneas. A esa tesis se añadió la defección (abandono de una causa con deslealtad) de Lerroux, provocada por su recelo hacia un Azaña que pactaba sin reserva con los socialistas. El resultado fue, como es conocido, la disolución de las Cortes en el otoño de 1933. Unos meses antes, el 28 de abril de 1933, Marcelino Pascua presentaba su dimisión como Director general de Sanidad.

Resulta difícil valorar el trabajo que llevaron a cabo los gobernantes del primer bienio republicano. Como ha señalado más de un autor, probablemente podrían haberlo hecho mejor (Tamames, 1988: 115-119). En cualquier caso, conviene recordar, que salvo raras excepciones como las de Alcalá Zamora, Maura, y en cierto modo, Largo Caballero, estaban faltos de experiencia en las tareas de gobierno. Con todo, a pesar de que se iniciaban en las funciones públicas, aquellos primeros gobernantes republicanos se plantearon en profundidad la modernización del país.

La sanidad, junto con la educación, se convirtieron en elementos claves para la modernización (Mazuecos, 1980). En esta ocasión, nos gustaría abordar la gevtin de Pascua como Director general de Sanidad y analizar las razones que le llevaron a presentar su dimisión. Utilizaremos como guía de nuestro recorrido, las actividades que generó la Dirección general y que quedaron plasmadas en circulares, ordenes ministeriales, decretos, etc, además de la prensa periódica y la prensa profesional para 
conocer la valoración que mereció su labor en diversos colectivos y acercarnos al contexto socio-político del momento. Antes, sin embargo, nos gustaría recordar, brevemente, las condiciones que acompañaron la incorporación de Marcelino Pascua a la actividad política.

\section{INTELECTUALES METIDOS A POLÍTICOS}

El período comprendido entre el final de la Dictadura de Primo de Rivera, en los últimos días de enero de 1930, y la proclamación de la Segunda República, en abril de 1931, conoció la coincidencia de buena parte de los intelectuales del país en un propósito colectivo de carácter político. En abril de 1931, afirman Javier Tusell y Genoveva Queipo de LLano en una interesante monografía sobre Los intelectuales y la política (1990: 10-11): la intelectualidad habría jugado un papel decisivo en el colapso de la monarquía de la Restauración. El nuevo régimen nació con un elevadísimo número de intelectuales y profesores en las filas de su clase política.

La postura de Ortega (1883-1956), por ejemplo (Tusell, Queipó, 1990: 114-115), fue más allá del pugilato casi personal que había mantenido con Primo de Rivera. Su posición estaba más próxima a la de un republicanismo, estrictamente liberal, apoyado en ambientes universitarios, que se plasmaría en la Agrupación al Servicio de la República.

El manifiesto de la Agrupación, que debió redactarse en la primera quincena de enero de 1931, sólo se hizo público el 9 de febrero de ese mismo año, tras la vuelta a las garantías constitucionales que habían sido suspendidas, con la correspondiente declaración del estado de guerra, por la sublevación de Jaca. Si el proyecto de crear la Agrupación no había nacido originariamente de Ortega, el manifiesto fundacional era suyo a pesar de que las firmas del mismo (Marañón, Ortega, Pérez de Ayala) figuraban en estricto orden alfabético. El manifiesto comenzaba con la apelación a los sectores intelectuales y profesionales españoles, a quien decía estar especialmente dirigido (Tusell, Queipó, 1990:181):
Cuando la historia de un pueblo fluye dentro de su normalidad cotidiana, parece lícito que cada cual viva atento sólo a su oficio y entregado a su vocación. Pero cuando llegan tiempos de crisis profunda, en que rota o caduca toda normalidad, van a decidirse los nuevos destinos nacionales, es obligatorio para todos salir de su profesión y ponerse sin reservas al servicio de la necesidad pública

Ortega, gracias a la Agrupación al Servicio de la República, consiguió aglutinar, aunque tardíamente, a un grupo intelectual de valía importantísima. Entre aquel grupo de intelectuales destacan, entre otros, el novelista Ramón Pérez de Ayala (1881-1962), el catedrático de Derecho Penal, Luis Jiménez de Asúa (1889-1970), o el mismo Gregorio Marañón Posadillo (1887-1960).

Frente a lo que representaba la Agrupación al Servicio de la República, hubo un sector intelectual que demandaba, no sólo un cambio de régimen, sino también un cambio de sociedad (Tusell, Queipó, 1990: 151-162). En este sentido se explica que estuvieran mucho más cercanos a las fórmulas socialistas que a lo que representó la Agrupación al Servicio de la República. Esta fue la posición de un Luis Araquistain (1886-1959), quien no había tenido una adscripción al Partido Socialista Obrero Español (PSOE) a lo largo de la mayor parte de la Dictadura de Primo de Rivera. Esta puede considerarse también, aunque en otro plano, la posición de Julio Alvarez del Vayo (1890-1975).

Conviene recordar la relación que existió entre Luis Araquistain, Julio Alvarez del Vayo y el fisiólogo Juan Negrín (1892-1956). En la primavera de 1929, el doctor Negrín, como habían hecho Araquistain y Alvarez del Vayo, ingresaba en el PSOE. Como señala Juan Marichal (1990: 87-106), dado el corto número de intelectuales que formaban parte del partido, su incorporación fue comentada tanto por El Socialista como por El Sol.

La entrada oficial del doctor Negrín en la actividad política nacional (como en el caso de otros integrantes de la generación de 1914) fue en 1931, al ser elegido diputado a las Cortes Constituyentes por su provincia natal, la de La Palmas. A Negrín le acompañaría, en la conse- 
cución del acta de diputado por Las Palmas, otro socialista, el doctor Marcelino Pascua Martínez. De hecho, fueron Juan Negrín e Indalecio Prieto quienes recomendaron a Miguel Maura, ministro de la Gobernación en el primer gabinete de la República, el nombramiento de Marcelino Pascua como Director general de Sanidad. Maura llegó a declarar, en más de una ocasión, que este nombramiento era aquel del que se había sentido más satisfecho de todos los que llevó a cabo durante su periodo ministerial (Moya, 1977).

\section{LA PROPUESTA ORGANIZATIVA DE PASCUA: DE LA BUROCRACIA A LA GESTIÓN POLÍTICA}

\section{Los cambios organizativos en la Dirección general de Sanidad}

El 15 de abril de 1931, Marcelino Pascua Martínez, sustituía a José A. Palanca en el cargo de Director general de Sanidad. En los primeros días se vio obligado a despachar una cantidad importante y variopinta de asuntos: desde el tráfico de estupefacientes y la delimitación de los partidos farmacéuticos a cuestiones relacionadas con los uniformes de las enfermeras. Quizás por ello, el 25 de abril de 1931 el ministro de la Gobernación, dependencia ministerial donde se encontraba adscrita la Dirección general de Sanidad, firmaba una orden ministerial con el siguiente contenido:

[...] a fin de que VI (Director general de Sanidad) pueda dedicar el mayor tiempo y atención al estudio de la multitud de problemas que ha encontrado planteados al hacerse cargo de esa Dirección general [...] éste Ministerio se ha servido disponer que las Inspecciones Generales de Sanidad exterior, comunicaciones y transporte, Sanidad interior, Instituciones sanitarias y Sanidad veterinaria, a partir de esta fecha, se encarguen de tramitar y resolver los asuntos de su peculiar competencia $[. .$.

Se trataba de liberar al Director general de las obligaciones burocráticas y los asuntos de trámite y poder dedicar, así, más tiempo a la gestión política. Pascua, en una de las múlti- ples entrevistas que concedió con motivo de su cese ( $\propto E \mathrm{El}$ director de Sanidad habla para 'Luz'», 1933: 4-5), llegó a declarar que una de las cosas que más le sorprendió al hacerse cargo de la Dirección general fue la inútil cantidad de legalismo y expedientes que hay en la administración del Estado para añadir a continuación ¿Cuántas veces se tiene que estampar la firma sin enterarse apenas de los asuntos?

Hay que indicar, sin embargo, que los esfuerzos de Pascua para dotar a la Dirección general de Sanidad de los instrumentos de una administración moderna solo tuvieron su recompensa al final de su mandato. En enero de 1933, a través de una Orden ministerial, se creaba dentro del organigrama de la Dirección general de Sanidad una Secretaria General Técnica. Marcelino Pascua justificaba su creación con estas palabras: Instrumento que en realidad demuestra como absolutamente imprescindible al objeto de que la Dirección propia rinda mucho más en su aspecto técnico al suprimirle el agobio de tanta tramitación burocrática y social de casi nulo valor constructivo. Para ocupar el cargo de Secretario general de la Dirección general de Sanidad, Marcelino Pascua nombró a José Estellés Salarich (Orden ministerial de 28 de febrero de 1933).

Entre las funciones que se asignaban a la nueva dependencia administrativa figuraban las siguientes:

1. Coordinar las secciones de la Dirección general

2. Ejercer la secretaria del Consejo Nacional de Sanidad

3. Establecer relación con la prensa política y profesional

4. Traducción de documentos extranjeros

5. Formación de una biblioteca especializada

6. Elaboración de memorias periódicas generales

De acuerdo con las funciones asignadas, dentro de la Secretaria General Técnica se contemplaban un total de cinco secciones: 
1. Registro general, información y reclamaciones

2. Asuntos generales

3. Personal dependiente de la Dirección general de Sanidad Secretaria del Consejo Nacional de Sanidad.

4. Secretaría del Consejo Nacional de Sanidad.

5. Prensa, biblioteca y publicaciones.

\section{Los colaboradores}

El grupo de colaboradores que acompañó a Marcelino Pascua en su gestión al frente de la sanidad nacional, presentaba dos características fundamentales: su vinculación a la Escuela Nacional de Sanidad y su relación, desde la condición de becarios, con la Fundación Rockefeller ${ }^{2}$ Este último era el caso, por ejemplo, de Julio Bravo Frías, nombrado por Pascua Jefe de la Sección de Higiene Social y Propaganda y de Manuel Tapia Fernández, director del Hospital Nacional de Enfermedades Infecciosas durante el mandato de Marcelino Pascua como Director general de Sanidad.

El primer nombramiento que llevó a cabo Marcelino Pascua fue el de Román García Duran como Inspector general de Sanidad interior (24-4-1931). El nuevo Inspector general ocupaba, desde julio de 1924, la plaza de profesor de Medicina Social y Legislación Sanitaria de la Escuela Nacional de Sanidad. Hay que indicar, sin embargo, que unas semanas después, el 6 de mayo de 1931, Santiago Ruesta Marco era nombrado nuevo Inspector general en sustitución de García Duran.

Al nombramiento de García Durán sucedió, el 25 de abril de 1931, el de Sadí de Buen como Inspector general de Instituciones Sanitarias. Jefe de Sección del Instituto Nacional de Higiene y colaborador de Gustavo Pittaluga

(2) Para contextualizar la importancia de la Fundación Rockefeller en el desarrollo científico y sanitario en la España de los años veinte y treinta, se puede consultar el trabajo «La Fundación Rockefeller y España, 1914-1939. Un acuerdo para la modernización cientifica y sanitaria» (Rodríguez Ocaña, Bernabeu Mestre, Barona, 1996). en la Cátedra de Parasitología de la Facultad de Medicina de Madrid, Sadí de Buen sustituyó en el cargo a Víctor María Cortezo Collantes, quien había sido cesado y depurado por las responsabilidades políticas que contrajo durante la Dictadura de Primo de Rivera. Sadí de Buen se convirtió en la persona de confianza de Pascua. De hecho durante las ausencias del mismo, como ocurrió en septiembre de 1931, era el encargado de asumir la Dirección general.

El organigrama de las Inspecciones generales se completaría con los nombramientos de Manuel Torres Grima como Inspector general de Sanidad Exterior, Comunicaciones y Transporte (27-4-31) y con la confirmación de José Niceto García Armendaritz como Inspector general de Higiene y Sanidad Veterinaria. En relación con esta última Inspección general, un decreto de junio de 1931, ordenaba su supresión y se creaba una Inspección general de las mismas características aunque dependiente del Ministerio de Fomento.

\section{Las primeras iniciativas}

El mismo mes de abril de 1931, el día 29, se promulgaba un decreto de cese de los miembros que formaban parte del Consejo Nacional de Sanidad y se procedía a su renovación. Además de los consejeros natos, se nombraban a título personal, por sus especiales conocimientos científicos, entre otros, a Gregorio Marañón, José Sánchez Covisa, Luis Sayé (Director del Servicio de Asistencia Social y Lucha Antituberculosa de Barcelona) o Manuel Martín Salazar, exdirector general de Sanidad.

Además de trabajar en la preparación e informe de normativas tan relevantes como la ley orgánica de Sanidad, el Consejo Nacional de Sanidad estaba llamado a jugar un papel fundamental en el proceso de transferencias sanitarias a Cataluña. Como se recogía en el Decreto de 20 de mayo de 1931 que regulaba dichas transferencias, el Consejo debía informar al Ministerio sobre las diferencias que pudieran surgir y, en lo relativo a las soluciones o recomendaciones, se indicaba será necesariamente oído [el Consejo] en la aprobación definitiva del plan de transferencias. De hecho, a partir del problema de las transferen- 
cias a la Generalitat de Cataluña se generó un interesante debate parlamentario y social sobre el modelo de sistema sanitario que se debía desarrollar (El debate sobre el Estatuto de Cataluña y la Sanidad, 1932).

Entre las nuevas incorporaciones al Consejo Nacional de Sanidad destaca la del Presidente de la Asociación de Titulares, Inspectores Municipales de Sanidad, el doctor Ossorio. La incorporación se producía a instancias del propio Director general y buscaba, como manifestaría el propio Pascua en unas declaraciones a la revista Regeneración Médica (Declaraciones del Director de Sanidad, 1933), atender las reivindicaciones del colectivo de médicos y farmacéuticos titulares y facilitar su intervención activa en la confección de la nueva ley orgánica de Sanidad.

El presidente de la Asociación de Titulares formo parte, a propuesta de Marcelino Pascua, de dos de las ponencias que mas podían afectar a las funciones e intereses de los inspectores municipales de Sanidad: la de la Higiene rural y la de la Práctica profesional. Sin embargo, a juicio del Director general de Sanidad, su colaboración en las fructiferas tareas del Consejo fue nula: de las dieciséis o diecisiete reuniones que dichas ponencias celebraron para elaborar el texto de la ley, sólo a una o dos acudió el señor Ossorio. Los titulares dirán si ello les satisface. Las dificultades de entendimiento con el colectivo de titulares fueron manifiestas desde el primer momento. Las reivindicaciones de los médicos y farmacéuticos titulares chocaban con el modelo de sistema sanitario que pretendía desarrollar Pascua.

El deterioro de relaciones entre Pascua y el colectivo de titulares sanitarios fue evidente y progresivo. Estos últimos llegaron a organizar auténticas campañas, como ocurrió con el envío masivo de telegramas solicitando el cese de Pascua, además de utilizar la prensa profesional para desprestigiar y criticar la posición del Director general, de modo particular la revista Vida Médica (Hechos y palabras del Director general de Sanidad, 1932; El seguro de enfermedad, 1932). Pascua atribuía la reacción del colectivo de titulares a comportamientos corporativistas. Además de denunciar la creencia, extendida entrc cl colcctivo de médicos y farmacéuticos, de considerar al Director general de Sanidad como una especie de abogado defensor de sus intereses ${ }^{3}$, situaba el origen del conflicto en cl antagonismo que existía entre médicos, farmacéuticos y «sanitarios»: [...] diremos, resumiéndolo en una frase dura, pero real, que este antagonismo nace de que la sanidad quita enfermos (Palabras del Director general de Sanidad, 1932: 1-2; Director de Sanidad habla para Luz, 1933).

Otra de las cuestiones que para Pascua estaban en el origen del conflicto de los titulares era él, a su juicio, excesivo número de licenciados en medicina. Así en unas declaraciones a la revista «Luz» que aparecen recogidas en «Vida Médica (El director de Sanidad habla para «Luz», 1933; 4) llegaba a afirmar lo siguiente: mientras sigan sobrando los médicos [...] los titulares y los demás médicos sufrirán terribles perjuicios, y la ciencia médica también, ya que el nivel ético y técnico se relaja $[. .$.$] se impone con urgencia suprimir$ facultades y limitar la producción de médicos.

Para Pascua, aceptar la principal reivindicación que planteaba el colectivo de titulares, es decir su pase a funcionarios del Estado (Asociación Nacional del Cuerpo de Médicos Titulares.., 1932), suponía hipotecar el futuro del modelo de asistencia médica que intentaba implantar (Problemas que plantean los médicos titulares, 1933: 81-82):

El comité de titulares actuará como estime conveniente. Por lo que a mi respecta [...] he de seguir fielmente mi ruta prosiguiendo en mi tarea de organizar sólidamente sobre bases científicas la sanidad en el medio rural [...] hasta que la higiene pública y la medicina preventiva en el campo español sea una novedad tangible sobre una base de nacionalización. Y tras ella, y a veces conjuntamente, irá surgiendo, asimismo, la socialización [sic] de la medicina curativa y de la asistencia. $Y$ sólo dentro de estos términos netos, de absoluto y eficaz, servicio público, con-

(3) En unas declaraciones al semanario «Luz» (Director de Sanidad habla para Luz, 1933), afirmaba: el Director general de Sanidad deber estar ocupado en el bienestar comán, incluso, a veces, en contra de los médicos, cuando éstos entren en conflicto con los intereses de la colectividad. 
cibo yo la incorporación de los actuales titulares a los escalafones del Estado.

Otro organismo que se vio afectado por las remodelaciones fue el Consejo de Protección a la Infancia. Como se indicaba en el Decreto de 14 de agosto de 1931: se precisa ya de una renovación, poniendo dicha legislación de acuerdo con las orientaciones más modernas [...]. Entre las novedades que introducía e] Decreto, además de declarar el Consejo Superior de Protección a la Infancia una Institución de Beneficencia del Estado, hay que destacar la creación de una Comisión Permanente que debía mantener reuniones semanales. Para garantizar el funcionamiento de la Comisión se dotó una partida presupuestaria destinada a cubrir las dietas de asistencia de sus miembros. Se trataba de otorgar dinamismo a la Institución y avanzar en la formulación de los proyectos que debían desarrollar y supervisar las diferentes secciones (Puericultura y Primera infancia, Asistencia social, jurídica y legislativa, Vagancia y delincuencia).

\section{BASES PARA UNA REFORMA DE LA SANIDAD NACIONAL}

Habría que esperar el paréntesis veraniego de 1931 para que se pusieran en marcha algunas de las iniciativas más importantes impulsadas por Marcelino Pascua durante su mandato. El 13 de octubre de 1931 se promulgaba el Decreto de creación de una Comisión Permanente de Investigaciones Sanitarias. Dos meses después, el 13 de diciembre, sendos Decretos creaban las Secciones de Ingeniería y Arquitectura Sanitaria, de Higiene Infantil e Higiene Social y Propaganda. En medio, a través de un Decreto de 12 de noviembre de 1931, se crcaba un Consejo Superior Psiquiátrico.

Dicho Consejo, dependiente de la Dirección general de Sanidad, tenía el encargo de asesorar a la Sección de Psiquiatría e Higiene Mental. Las reformas relativas a salud mental se completaron con la creación, en abril de 1932, de un Patronato de Asistencia Social Psiquiátrica y con la puesta en marcha, a través de la Orden ministerial de 16 de mayo de 1932 , de un programa de formación de personal sanitario subal- terno para establecimientos psiquiátricos. ${ }^{4}$ Como responsable médico de la Sección de Psiquiatría e Higiene Mental se nombró a José Germain Cebrián (Orden ministerial de 31 de marzo de 1933). Germain impartía docencia en la Escuela Nacional de Sanidad como profesor agregado de Higiene del trabajo, industrial i profesional, formaba parte del Comité Internacional de Higiene Mental en la Industria, era miembro de la Asociación Internacional de Psicotecnia, además de vocal del Comité Internacional de tests (Bernabeu, 1994: 76).

\section{La Comisión Permanente de Investigaciones Sanitarias}

Hay que indicar que el nuevo organismo pasaba a depender, de forma directa, de la $\mathrm{Di}$ rección general de Sanidad. La Comisión debía sugerir los grandes temas de investigación que las circunstancias epidemiológicas y sanitarias del país aconsejasen. El Decreto destacaba la importancia de conseguir una adecuada formación profesional del personal sanitario y médico a través del fomento de la investigación científica.

Otro aspecto que se quería desarrollar con la creación de la Comisión Permanente de Investigaciones Sanitarias guardaba relación con el deseo de aumentar las relaciones con los organismos sanitarios internacionales y con los pensionados en el cxtranjero. De forma particular se destacaba la necesidad de incrementar las relaciones con los países iberoamericanos:

Se pondrá asimismo en relación con las Administraciones sanitarias y con los Centros de estudios de las naciones hispanoamericanas $[. .$.$] posible intercambio de personas y$ temas de estudios médico-científicos [...] lazos espirituales e intelectuales con los paises de lengua española en América

(4) El Decreto de 12 de noviembre de 1931 recogía en su preámbulo las siguientes palabras: Es preciso que de aqui en adelante, desaparesca el estado de cosas que entregaba a los enfermos psíquicos al cuidado de personas sin preparación alguna previa, ni psiquiátrica, ni médica. Consecuencia de esto ha sido el tratamiento inadecuado $e$ incluso perjudicial a que han estado sometidos los enfermos mentales. Los progresos de la ciencia psiquiarrica y las modernas ideas de la higiene mental exigen la solución. 
La Comisión estaba formada por Francisco Tello, como Presidente. Como vocales fueron nombrados Gregorio Marañón, Gustavo Pittaluga, Manuel Tapia y Sadí de Buen. Como Secretario fue nombrado José Hernández Guerra, quien falleció el 5 de noviembre de 1932, y fue sustituido por Francisco Martínez Nevot. En la tabla adjunta se pueden comprobar los temas de investigación que se subvencionaron en 1932 (Martínez Nevot, 1933: 645-652):

1. Estudio bacteriológico y epidemiológico de las relaciones entre la fiebre de Malta y el aborto epidémico

2. Estudio de un foco endémico de lepra

3. Estudio sobre la transmisión de la peste

4. Ubicación del estiércol y contagio por medio de las moscas

5. Estudio de la evolución de las larvas de anquilostomas en el ambiente rural y estudio de la evolución y transmisión de la hymenolepis

6. Estudio sobre micología española

7. Constitución química de los alimentos españoles

8. Estudio geográfico del bocio y sus relaciones con la composición química de aguas, terrenos y alimentación

9. Estudio de los focos de bilharziosis de Lorca y Moguer

10. Aspecto sanitario de la pneumoconiosis

11. Estudio bacteriológico de las aguas residuales de Madrid, en sus relaciones con la difusión de la fiebre tifoidea y grupo de enfermedades afines y estudio de portadores de gérmenes en el hombre $y$ en animales

12. Anofelismo sin paludismo en la zona de Aranjuez

13. Poder fitotóxico de los sueros

14. Relaciones entre la constitución (biotipología y endocrinología) y el traco- ma, y confección de un fichero de tracomatosos

15. Aspecto sanitario del problema de las vitaminas

Para poder obtener las subvenciones, los responsables de cada proyecto de investigación debían presentar una memoria. Además de realizar un estado de la cuestión sobre el tema que se proponía, se tenía que indicar el modo en el que estaba previsto proseguir las investigaciones, el personal que se consideraba imprescindible y el avance aproximado de gas. tos. Los investigadores se comprometían a enviar unos resúmenes mensuales informando de la marcha de las investigaciones.

La Comisión, por su parte, se comprometía a proporcionar el material científico necesario para llevar adelante las investigaciones, además de los libros, monografías y revistas que fuese necesario adquirir para poder documentarse. La cuantía de las bolsas de trabajo oscilaban entre las 300 y las 500 pesetas mensuales, según las circunstancias económicas de los becarios. Las dietas diarias, cuando los becarios abandonaban la residencia habitual, oscilaba entre las 15,20 y 35 pesetas, según los casos.

\section{La creación de nuevas secciones técnicas}

Otra de las iniciativas que se pusieron en marcha en el otoño de 1931 fue, tal como hemos indicado, la creación de nuevas Secciones técnicas de la Dirección general (Decretos de 13 de diciembre de 1931) que se unían a la de Psiquiatría e Higiene Mental (Decreto de 12 de noviembre de 1931): Ingeniería y Arquitectura Sanitaria, Higiene Infantil, Higiene Social y Propaganda. A todas estas secciones se sumaría, en los primeros meses de 1933, la de $\mathrm{Hi}$ giene de la Alimentación.

Con la Sección de Ingeniería y Arquitectura Sanitaria, dependiente de la Inspección general de Instituciones Sanitarias, se quería acometer la solución de los problemas de ingeniería ligados con la higiene y la sanidad de las ciudades, como también los trabajos de saneamiento del medio rural.

El tema de la sanidad y la higiene rural provocaría un conflicto de competencias entre 
la Dirección general de Sanidad, dirigida por Pascua, y el Ministerio de Agricultura, Industria y Comercio de Marcelino Domingo. El incidente que vamos a relatar resulta un buen ejemplo del celo y el interés que mostraba Pascua para conseguir una acción sanitaria coordinada y eficaz. En enero de 1933 Pascua dirigía un escrito al ministro Marcelino Domingo donde se manifestaba en los términos siguientes (PS. Madrid, 240):

Informaciones llegadas a este Ministerio, denuncian que el Instituto de Reforma Agraria, ha creado una sección de Higiene de la Vivienda Rural y encargado de su jefatura a persona extraña al Cuerpo de Sanidad $\mathrm{Na}$ cional [...] justamente ocurre ello cuando la Dirección general de Sanidad ha puesto en marcha en un año 16 Centros de Higiene Rural.

En efecto, a través de una Orden ministerial de 22 de abril de 1932, se creaban 15 Centros secundarios de Higiene rurat. Estaba previsto crear un total de 180 Centros rurales de Higiene (El presupuesto de Sanidad, 1933: 63-64). Para formar al personal sanitario de todos estos centros se contaba con el Centro de Higiene de Vallecas. Este último proyecto estaba cofinanciado por la Fundación Rockefeller y tenía la condición de institución docente asociada a la Escuela Nacional de Sanidad y a la futura Escuela Nacional de Enfermeras Visitadoras, otra de las iniciativas que contó con la ayuda financiera de la Fundación Rockefeller (Bernabeu, Gascón, 1995; Rodríguez Ocaña, Bernabeu, Barona, 1997).

Una Sección que alcanzó gran importancia fue la de Higiene Infantil. Dependiente de la Inspección general de Instituciones Sanitarias, el objetivo de la Sección no era otro que el de luchar contra la mortalidad infantil y aspectos con ella relacionado. ${ }^{5}$ Contaba con los departamentos de mortalidad materna, de morti-natalidad, e higiene prenatal y pre-escolar. Además, a

(5) En la Orden ministerial de 30 de marzo de 1932 se afirmaba: Las causas de la elevada mortalidad infantil son en cierto modo evitables, puesto que muchas de ellas responden a falta de higiene durante el embarazo y la crianza del niño y de la incultura y la falta de orientación sanitaria, existiendo no pocas provincias que carecen de los más elementales servicios de higiene infantil y otras en las cuales los esfuerzos particulares y oficiales, los fallos de la coordinación y orientación sanitaria, no surten la eficacia [...]. través de una Orden ministerial de 30 de marzo de 1932, se creaban en todos los Institutos provinciales de Higiene, Servicios de Higiene Infantil que debían contar con consultas de higiene prenatal, de lactantes y de higiene escolar. Una Orden ministerial, de 11 de agosto de 1932, permitía crear, a través de la correspondiente dotación presupuestaria, Dispensarios móviles de Higiene Infantil. De hecho, por medio de una Orden de 31 de marzo de 1933, se creaban, entre otros, los dispensarios móviles de Burgos, Avila, Segovia y Teruel. A través de la Orden ministerial de 29 de marzo de 1933 se nombró a Juan Bravo Frías responsable médico de la Sección de Higiene Infantil.

La tercera de la secciones que se pusieron en marcha, en el otoño de 1931, fue la de Higiene Social y Propaganda. La nueva Sección debía asumir las funciones de asesoramiento [...] y ejecución en materias que tanto afectan a la salud pública, como las comprendidas en la higiene social, alcoholismo, enfermedades sociales, cáncer, etc. [...] y propaganda de higiene personal y pública.

Entre las actividades que llegó a iniciar la Sección de Higiene Social y Propaganda podemos citar el concurso de carteles de abril de 1933 (Orden ministerial de 4 de abril). Se proponía desarrollar dos proyectos: uno en favor de la lactancia materna (lo mejor para evitar la muerte de los niños de pecho es la leche de la madre) y otro para destacar la vigilancia médica en la lactancia (si no puedes criar a tu hijo de pecho, consulta al médico antes de darle biberón).

La última de las secciones incorporadas por Pascua al organigrama de la Dirección general de Sanidad fue la Sección de Higiene de la Alimentación. En febrero de 1933, Cesar Nistal Martínez era nombrado Jefe técnico de la Sección. El 24 de marzo del mismo año, a través de una Orden ministerial, se ponía en marcha la Comisión encargada de estudiar el régimen de funcionamiento de los servicios que tenía que desarrollar la nueva Sección.

\section{Otras actuaciones}

Durante el período en el que Pascua estuvo al frente de la Dirección general de 
Sanidad, además de Ios aspectos que acabamos de exponer (salud mental, higiene infantil, propaganda sanitaria, higiene de los alimentos o ingeniería sanitaria) se intensificó la lucha antituberculosa a través de la construcción de nuevos dispensarios, de preventorios infantiles y de sanatorios. Lo mismo ocurrió con la lucha antivenérea, donde tan importante servicio sanitario pasó a depender presupuestariamente del Estado y dejo de ser mantenido mediante irregulares exaccioncs a las prostitutas.

En relación con la lucha antituberculosa, conviene señalar las dificultades que le planteó a Pascua la decisión de sacar a concurso público todas las plazas antituberculosas que se habían obtenido por simple nombramiento. Hay que indicar, sin embargo, como reconocía el propio Pascua, que la medida fue aplicada sin contemplaciones: Por anticipado tenían el pleito perdido, pues mi idea, que lleve a efecto, y que tenía forzosamente buena acogida en la opinión pública y el asenso de acuerdos del Colegio y del Sindicato Médico, era sacar a oposiciones públicas [...] todas las plazas que se habian obtenido por nombramiento directo y personal (El director de Sanidad habla para «Luz», 1933).

La gestión sanitaria se completo con una importante política de restricción de estupefacientes y el refuerzo de la lucha antitracomatosa. Además de avanzar en proyectos como la creación de una Escuela Nacional de Enfermeras Visitadoras, se mejoró la situación presupuestaria y organizativa de todo un conjunto de instituciones que dependían de la Dirección general de Sanidad: Instituto Nacional de Higiene, Hospital Nacional de Enfermedades Infecciosas, Escuela Nacional de Sanidad (Bernabeu, 1994), Escuela Nacional de Puericultura, o el Instituto de Farmacobiología. Ocuparon la dirección de todas estas instituciones, respectivamente: Jorge Francisco Tello Muñoz, Manuel Tapia Martínez, Gustavo Pittaluga, José García Diestro y Teófilo Hernando Ortega. En mayo de 1932 se adscribía a la Dirección general de Sanidad el Instituto $\mathrm{Na}$ cional del Cáncer y se procedía a la incautación de la Leprosería de Fontilles (Bernabeu, Ballester, 1991).

\section{EL BALANCE DE UNA GESTIÓN: UN PROYECTO INACABADO}

El 28 de abril de 1933 se publicaba un Decreto aceptando, a propuesta del ministro de la Gobernación, Casares Quiroga, la dimisión que, como Director general de Sanidad, había presentado Marcelino Pascua Martínez.

Unos meses antes, en enero de ese mismo año, en un artículo publicado en la Revista de Sanidad e Iigiene Pública (1933; 8/1: 59-61) con el título de Presupuesto de Sanidad, Pascua justificaba las iniciativas que se habían llevado a cabo en la Dirección general de Sanidad desde abril de 1931 y establecía las líneas directrices que debían guiar la política sanitaria de la Segunda República.

Marcelino Pascua denunciaba el vergonzoso atraso en que tradicionalmente se había tenido al aparato sanitario del Estado, y, para poner de manifiesto el interés de la Segunda República por el cuidado de la salud pública y la reorganización de los servicios sanitarios del país, acompañaba un cuadro con los presupuestos ordinarios de la Dirección gencral de

\begin{tabular}{|l|c|}
\hline AÑOS & $\begin{array}{c}\text { PRESUPUESTOS } \\
\text { ORDINARIOS } \\
\text { (en millones de pesetas) }\end{array}$ \\
\hline $1920-21$ & 6.619 .300 \\
\hline $1921-22$ & 6.619 .300 \\
\hline $1922-23$ & 8.250 .450 \\
\hline $1923-24$ & 7.050 .450 \\
\hline $1924-25$ & 7.721 .600 \\
\hline $1925-26$ & 7.440 .600 \\
\hline 1927 & 8.605 .650 \\
\hline 1928 & 8.235 .550 \\
\hline 1929 & 10.326 .740 \\
\hline 1930 & 10.290 .982 \\
\hline 1931 & 9.990 .082 \\
\hline 1932 & 15.582 .807 \\
\hline 1933 & 31.432 .690 \\
\hline & \\
\hline
\end{tabular}


Sanidad desde 1920-1921 hasta el mismo año de 1933 (Presupuesto, 1933: 58):

Tras resumir los logros más importantes conseguidos en 1931 y 1932, exponía las actividades que en su opinión se debían desarrollar en el futuro. Destacaba su propuesta de presentar ante las Cortes una ley orgánica de Sanidad. Por último, además de proponer la abolición de la prostitución reglamentada, citaba, entre otras, las líneas de trabajo sobre las que se debía profundizar:

1. La higiene de la alimentación, particularmente el abastecimiento de la leche

2. La modernización, humanización más bien, de hospitales, manicomios, etc.

3. El fomento de la lucha anticancerosa en su aspecto público, esto es, el tratamiento y diagnóstico precoz de tumores malignos

4. El gran problema de la asistencia y prevención de la ceguera y otras incapacidades

\section{La higiene industrial}

6. La insostenible situación del profesionalismo médico y farmacéutico

7. La preparación del ambiente y estudios de rigurosidad científica y moral sobre el problema del control de la natalidad

8. La organización del Instituto de Investigaciones hidrominerales

Las palabras finales, que Marcelino Pascua incluía en el citado artículo, son reveladoras del proyecto de reforma sanitaria que defendía y al que hemos aludido a lo largo del trabajo: España no entrará en una reorganización sanitaria, muy particularmente en su aspecto de medicina curativa de gran fuste $y$ escala, hasta que no se implante el seguro de enfermedad, aplicable a grandes masas de población. Este será el momento cumbre y la vía de progreso por donde se llegue a la nacionalización de la medicina curativa y se refuerce y consolide la estatificación de la preventiva.
Como ya se ha señalado, el futuro de la salud pública y la medicina preventiva pasaban, a juicio de Pascua, por implantar un modelo de asistencia médica colectivizada.

A Marcelino Pascua le sustituyó, en mayo de 1933, Julio Bejarano. quien presentó su dimisión el 15 de septiembre de ese mismo año, cuando ocupó el ministerio de Gobernación Diego Martínez Barrios. El último Director general de Sanidad del bienio transformador fue José Verdes Montenegro. Nombrado el 20 de septiembre de 1933, Verdes fue cesado el 12 de octubre de ese mismo año, cuando ocupo la cartera de Gobernación Manuel Rico Avelló. A Verdes Montenegro le sustituyó José María Gutiérrez Barreal.

Entre las primeras medidas que puso en marcha la nueva administración sanitaria fue la de reintegrar, «una vez desaparecidas las causas que motivaron su cese», a Victor María Cortezo Collantes en el cargo de Inspector general de Instituciones Sanitarias. Así mismo, a través de la Orden ministerial de 25 de octubre, se anulaba la convocatoria para proveer la plaza de médico jefe de estadística de la Dirección general de Sanidad que había ocupado, de forma interina, Marcelino Pascua, y se retrotraía al 22 de septiembre de 1933, dando así la posibilidad de que pudieran presentarse nuevas solicitudes. El 11 de septiembre de 1933, días antes de presentar su dimisión, Julio Bejarano, en su calidad de Director general de Sanidad, había hecho publica una circular donde convocaba el concurso-oposición para proveer dicha Jefatura. Finalmente, el 15 de noviembre de 1933, tras obtener el número uno en el concurso-oposición, Marcelino Pascua recibía el nombramiento de Jefe de Estadística Sanitaria de la Dirección general de Sanidad.

Hasta aquí el somero análisis de la gestión de Marcelino Pascua al frente de la Dirección general de Sanidad. A modo de conclusión podríamos destacar las principales líneas de trabajo que desarrolló o diseñó en su etapa de responsable de la Dirección general de Sanidad: el impulso de la investigación sanitaria y la institucionalización de la salud pública; la aplicación de una política de salud que incorporaba los supuestos conceptuales y metodoló- 
gicos de la estadística sanitaria, la epidemiología y la higiene pública; o la necesidad de coordinar la acción preventiva, curativa y rehabilitadora en el marco de un sistema nacional de salud. Además de recordar el coste político que le supuso el conflicto y el enfrentamiento con el importante colectivo de médicos y farmacéuticos titulares y los apoyos partidistas que estos despertaban.

Pero quizás proceda concluir también con la valoración política que hacía de su gestión el propio Pascua en abril de 1933 (El director de Sanidad habla para «Luz», 1933: 5):

Antes de despedirnos hablamos un poco de política en general, y Pascua se lamentaba de que la renovación de la estructura monárquica del Estado sea demasiado lenta, -falta audacia - nos dice- en la mayoría de los departamentos del Estado, y eso cohibe, en cierto grado, a otros donde pudiera haberla y donde se anhela que la haya [...] Pascua terminaba con estas frases: Al marcharme de este puesto deseo fervientemente que algún día me llamen de nuevo en circunstancias más favorables, donde pueda desarrollar más amplios planes y pueda hacerse una renovación profunda de ideas y personas.

Todavía confio en que la situación politica se oriente y defina mejor y yo pueda estar diez o quince años al frente de la Sanidad española, laborando por ella con entusiasmo

Las circunstancias políticas y los acontecimientos de julio de 1936 se encargaron de hacer imposibles los deseos de Pascua. Aunque volvió a prestar servicios políticos a la Segunda República, a través de su labor como embajador en Moscú y París, sería la recién creada Organización Mundial de la Salud (1948) la que se beneficiaría de los servicios profesionales de Marcelino Pascua a través de la dirección del nuevo Departamento de Estadística Sanitarias (Bernabeu, 1992).

\section{BIBLIOGRAFÍA}

1. Asociación Nacional del Cuerpo de Médicos Titulares Inspectores Municipales de Sanidad. Comité ejecutivo 1932; XI/343: 9.
2. Barona Villar Jl., Mancebo MF. José Puche Alvarez (1896-1979): Historia de un compromiso. Estudio biográfico y científico de un republicano español. València, Comissió per al Vè Centenari del descobriment d'America, 1989.

3. Bernabeu Mestre J. «Marcelino Pascua desde la perspectiva histórica». Las estadísticas demográfico-sanitarias. I Encuentro Marcelino Pascua. Madrid, Centro Nacional de Epidemiología; 1992.p. 11-15.

4. Bernabeu Mestre J. El papel de la Escuela Nacional de Sanidad en el desarrollo de la salud pública en España, 1924-1934. Rev San Hig Publica. 1994; 68: 65-89.

5. Bernabeu Mestre J, Ballester Artigues T. Lepra y sociedad en la España de la primera mitad del siglo XX: La Colonia Sanatorio de Fontilles (1908-1932) y su proceso de intervención por la Segunda República. Dynamis 1991; 11: 287-344.

6. Bernabeu Mestre J, Gascón Pérez E. El papel de la enfermería de salud pública en el desarrollo de la salud pública española (19231935): la visitadora sanitaria. Dynamis 1995; 15: 151-176.

7. Debate sobre el Estatuto de Cataluña y la Sanidad. Vida Médica 1932; 11 (361): 2-6.

8. Declaraciones del Director de Sanidad. Regeneración Mćdica 1933; 21 (6): 64-67.

9. Director de Sanidad habla para «Luz» (El). Vida Médica 1933; 12 (386): 4-5.

10. Domínguez $\mathrm{H}$. Con la lógica en la mano. Vida Médica 1932; XI/342: 1-2.

11. Estadella Arnó J. La Sanidad pública. Vida Médica 1933; XI/400 y 401: 4-6 y 4-5.

12. Hechos y palabras del Director general de Sanidad. Vida Médica 1932; XI/348: 1-2.

13. Homenaje al Director general de Sanidad. Rev. San. Hig. Pub. 1932; 7/11: 1148-1149.

14. Homenaje al doctor Pascua (Un). Vida Médica 1932; 23 (626): 7-9.

15. Marichal J. El intelectual y la política. Madrid: Publicaciones de la Residencia de Estudiantes/ CSIC; 1990.

16. Marset Campos P, Sáez Gómez JM, Martínez Navarro F. La Salud Pública durante el franquismo. Dynamis 1995; 15: 211-250. 
18. Martínez Nevot F. La Comisión Permanente de Investigaciones Sanitarias. Rev. San. Hig. Pub. 1933; 8/6: $6^{\circ}$ eración 1933; XXI(7): 79-82.

27. PS. Madrid/240. Archivo de la Guerra Civil de Salamanca.

28. Rodríguez Ocaña E, Menéndez Navarro A. El primer Congreso Nacional de Sanidad (Madrid, 1934) como sanción de la profesionalización médico-social en España. Rev San Hig Publica 1986; 60: 1095-1107.

29. Rodríguez Ocaña E, Bernabeu Mestre J, Barona JL. La Fundación Rockefeller y España, 1914-1939. Un acuerdo para la modernización científica y sanitaria. VI Congreso de la S.E.H.C.Y.T., Segovia-La Granja, septiembre de 1996 (en prensa).
30. Ruiz Majón O. El Partido Republicano Radical 1908-1936. Madrid: Tebas; 1976.

31. Sanidad en la República (La). Dos años de gestión. Madrid, Ministerio de la Gobernación, 1933.

32. Sanidad Nacional: disposiciones oficiales emanadas del Ministerio de la Gobernación y otros centros referentes a higiene pública y administración sanitaria (1903-1935), 32 vols. Madrid: Dirección General de Sanidad.

33. Tamames, R. La República. La era de Franco. Madrid: Alianza Editorial (Historia de España 7. Miguel Artola [ed]); 1988.

34. Tusell J, Queipo de Llano G. Los intelectuales y la República. Madrid: Nerea; 1990. 